\title{
Branch and Price for a Reliability Oriented DARP Model
}

\author{
Alain QUILLIOT \\ Université Blaise Pascal \\ LIMOS CNRS Laboratory, \\ LABEX IMOBS3 \\ Clermont-Ferrand 63000, France \\ Email: alain.quilliot@isima.fr
}

\author{
Samuel DELEPLANQUE \\ Université Blaise Pascal \\ LIMOS CNRS Laboratory \\ LABEX IMOBS3 \\ Clermont-Ferrand 63000, France \\ Email: deleplanque@isima.fr
}

\author{
Benoit BERNAY \\ Université Blaise Pascal \\ LIMOS CNRS Laboratory, \\ LABEX IMOBS3 \\ Clermont-Ferrand 63000, France \\ Email: bernay@isima.fr
}

\begin{abstract}
We deal here with a static decisional model related to the monitoring of a DARP (Dial and Ride) model which involves, on a closed industrial site, small electrical autonomous vehicles. Because of technological issues, we focus on reliability, and propose a model which assign requests to vehicles while minimizing Load/Unload transactions. We study this model through both a Branch/Price approach, which provides us with benchmarks, and insertion based heuristics, well-fitted to dynamic contexts.
\end{abstract}

Keywords: Branch and Price, DARP, Reliability, vehicle scheduling

\section{Introduction}

Current trend in mobility management is to the emergence of flexible reactive systems, which meet mobility demands in a dynamic way while implementing some vehicle sharing and while interacting, through advanced I.T technologies, with alternative transportation modes [16]: Dial and Ride systems, Car-Sharing and Car-Pooling systems (AUTOLIB...), Ride Sharing systems. Also, recent advances in artificial perception and remote control make now arise new generations of autonomous (without any driver) individual or collective electrical vehicles: Cycab, VIPA (Individual Autonomous Vehicles of LIGIER S.A)...[14], which are involved into the design of those new mobility services [10]. For this kind of systems, what matters is reliability, related to the steady flow of the traffic induced by the involved vehicle fleet: monitoring has to smooth, as much as possible, the trajectories of the vehicles and minimize orders which require complex interactions between the vehicles.

The model which we handle here, which may be viewed as an extension of interval graph coloring models, is typical of this new kind of problems. It derives from a case study about the management of a specific Dial and Ride system, which involves VIPA automated vehicles and works in real time as a "horizontal elevator". Constraints are the classical DARP constraints, but performance criterion focuses on Stop Minimization: we do in such a way that, as often as possible, vehicles follow their way while avoiding any break (deviation toward a parking place, load/unload transaction,...) in their trajectory. Though the practical problem has to be handled according to a dynamic

adfa, p. 1, 2011.

(C) Springer-Verlag Berlin Heidelberg 2011 
(on line) point of view, with performance evaluated through discrete event simulation, we consider here, in order to get benchmarks together with a better understanding of the problem, the related static (off line) ILP Stop Minimization decision model. We first deal with this model through a Branch/Price method (Section III). and experimentally check (Section V), that optimizing reliability gets close here to vehicle minimization as well as to global riding time minimization. Next we propose and test (sections IV and V) a greedy randomized insertion heuristic, specially well-fitted to on line contexts.

\section{$2 \quad$ A Static Model}

Automated VIPA Vehicles [10], run here along a closed circuit $\Gamma$, while meeting $D i$ al and Ride demands (see $[1,3,4,5]$ ). The nodes $\Gamma$ are denoted by $\{0 . . n=0\}$, and the vehicles always run in the same direction: if a demand is about the transportation of some load $\mathrm{L}$ from an origin o to some destination $\mathrm{d}$, then the trajectory of the vehicle which meets this demand is $\{o, o+1 \operatorname{Mod} n, o+2 \operatorname{Mod} n, . ., d)$. Circuit $\Gamma$ is made of a common track and of load/unload areas, according to figure 1 below:

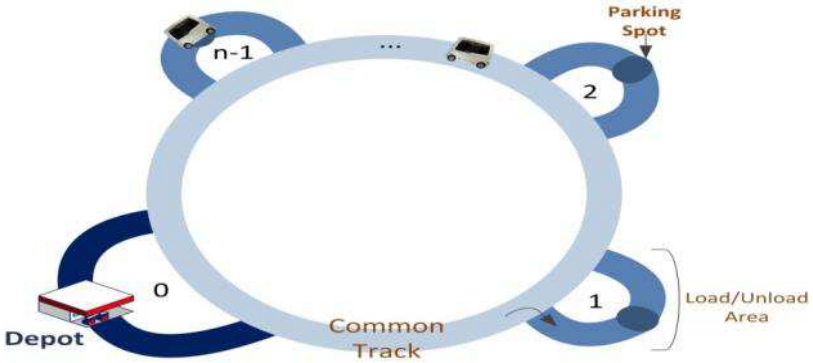

Figure 1

Node 0 is a Depot node, and the speed of the vehicles on the common track is constant (about $15 \mathrm{~km} / \mathrm{h}$ ): thus overtaking is forbidden on the main track, and, when a vehicle gets out some load/unload area, it has no priority on the other vehicles. Vehicles meet users on load/unload areas. Running along the whole circuit takes few minutes: so a vehicle which services a given user may run laps around $\Gamma$ before effectively servicing this user. Still we forbid such a user to stay a full tour inside the vehicle. Managing the vehicle fleet means, for every demand $\mathrm{j}$, accepting it or rejecting it, and, in case it is accepted, assigning it both a vehicle $\mathrm{k}$ and a waiting time $\mathrm{h}$, that is the number of laps the vehicle is going to run before servicing $\mathrm{j}$.

We adopt here a static point of view, and suppose that we are provided with $\mathrm{K}$ identical vehicles with capacity $\mathrm{C}$, all located at time 0 in the Depot node. Thus, a demand $\mathrm{j}=(\mathrm{o}(\mathrm{j}), \mathrm{d}(\mathrm{j}), \mathrm{L}(\mathrm{j}))$ is defined by an origin $\mathrm{o}(\mathrm{j})$ and a destination $\mathrm{d}(\mathrm{j})$, both in $\{0 . . \mathrm{n}\}$, together with a load $\mathrm{L}(\mathrm{j})$. Users ask for the system only when they are ready to move and demands do not involve time-windows. We denote by $\mathrm{H}$ the largest waiting time which is allowed. We suppose that $\mathrm{K}$ is large enough to avoid demand rejection. Since we are concerned here with reliability, which is correlated to load/unload transactions, the Stop-Number Problem consists in assigning vehicles and waiting times to 
users in such a way that vehicles minimize their Stop Number, i.e. stay as often as possible on the main track without moving onto the load/unload areas.

If we refer to standard Dial and Ride (see [3, 5, 7]), we see that individual riding times are almost fixed. Still, global riding time and individual waiting times (see [3, 5]) remain part of the problem. As experiments will show, minimizing the Stop Number also tends to minimize the Vehicle Number $\mathrm{K}$ as well as the global riding time.

An ILP Model: In order provide our problem with a formal framework, we unfold the circuit $\Gamma$ as a linear ordered set $\mathrm{I}(\Gamma)=\{0 . .(\mathrm{H}+2) . \mathrm{n}\}$, which we call the Stop Node Set. Let DEM $=\{\mathrm{j}=1 . . \mathrm{m}\}$ be the set of all demands $\mathrm{j}=(\mathrm{o}(\mathrm{j}), \mathrm{d}(\mathrm{j}), \mathrm{L}(\mathrm{j})), \mathrm{j}=1 . . \mathrm{m}$. In case $d(j)<o(j)$, we replace $d(j)$ by $d(j)+n$. By proceeding this way, we become able to associate, with every demand $\mathrm{j}=1 . . \mathrm{m}$, a collection of $\mathrm{H}+1$ discrete intervals $\mathrm{I}_{\mathrm{j}, \mathrm{h}}=$ $\{\mathrm{o}(\mathrm{j})+\mathrm{h} . \mathrm{n}, \ldots, \mathrm{d}(\mathrm{j})+\mathrm{h} . \mathrm{n}\}, \mathrm{h}=0 . . \mathrm{H}$, of the Stop Node Set. Clearly, we may suppose that every node $\mathrm{i}=1 . . \mathrm{n}-1$ is active, that means such that there exists at least one value $\mathrm{j}$ such that $\mathrm{i}=\mathrm{o}(\mathrm{j})$ or $\mathrm{i}=\mathrm{d}(\mathrm{j})$. Then, for any node $\mathrm{i} \in \mathrm{I}(\Gamma) \mathrm{i} \neq(\mathrm{H}+2)$.n, we set:

$A(i)=\{(j, h), j=1 . . m, h=0 . . H$, such that $o(j)+h . n \leq i<i+1 \leq d(j)+h . n\}$ : if a vehicle $k$ services $j \in A(i)$ after running $h$ times around $\Gamma$, that means according to waiting time $\mathrm{h}$, then $\mathrm{k}$ must be carrying load $\mathrm{L}(\mathrm{j})$ when moving from $\mathrm{i}$ to $\mathrm{i}+1$;

- $\quad B(i)=\{(j, h), j=1 . . m, h=0 . . H$, such that $(d(j)+h . n=i) O R(o(j)+h . n=i)\}:$ if a vehicle $k$ services $j \in A(i)$ according to waiting time $h$ then $k$ stops at $i$.

Then, if the number $\mathrm{K}$ of available vehicles is fixed, we get the following ILP model:

\section{Stop-Number(K) ILP Model:}

\{ Compute:

$\circ \quad \mathrm{Z}=\left(\mathrm{Z}_{\mathrm{j}, \mathrm{k}, \mathrm{h}}, \mathrm{j}=1 . . \mathrm{m}, \mathrm{k}=1 . . \mathrm{K}, \mathrm{h}=0 . . \mathrm{H}\right)$ with $\{0,1\}$ values $: \mathrm{Z}_{\mathrm{j}, \mathrm{k}, \mathrm{s}}=1$ if vehicle $\mathrm{k}$ services demand $\mathrm{j}$ according to waiting time $\mathrm{h}$;

$\circ \mathrm{T}=\left(\mathrm{T}_{\mathrm{k}, \mathrm{i}}, \mathrm{k}=1 . . \mathrm{K}, \mathrm{i}=1 . . \mathrm{n} .(\mathrm{H}+2)-1\right)$, with $\{0,1\}$ values $: \mathrm{T}_{\mathrm{k}, \mathrm{i}}=1$ if $\mathrm{i}$ is a stop node for vehicle $\mathrm{k}$.

Constraints :

○ For any $\mathrm{j}=1 . . \mathrm{m}, \Sigma_{\mathrm{k}, \mathrm{h}} \mathrm{Z}_{\mathrm{j}, \mathrm{k}, \mathrm{h}}=1 ; \quad\left({ }^{*} D_{j}\right.$ is serviced $\left.{ }^{*}\right)$

○ For any vehicle k, any node $\mathrm{i}=0 . .(\mathrm{H}+2) \cdot \mathrm{n}-1, \Sigma_{(\mathrm{j}, \mathrm{h}) \in \mathrm{A}(\mathrm{i})} \mathrm{L}(\mathrm{j}) . \mathrm{Z}_{\mathrm{j}, \mathrm{k}, \mathrm{h}} \leq \mathrm{C}$, (*Capacity Constraints*)

- For any vehicle $\mathrm{k}$, any stop node $\mathrm{i}=0 . .(\mathrm{H}+2) . \mathrm{n}-1$, any $(\mathrm{j}, \mathrm{h}) \in \mathrm{B}(\mathrm{i})$ : $\mathrm{Z}_{\mathrm{j}, \mathrm{k}, \mathrm{h}} \leq \mathrm{T}_{\mathrm{k}, \mathrm{i}}$ ( ${ }^{*}$ Coupling Constraints $*$ ).

Minimize : $\left.\Sigma_{\mathrm{k}, \mathrm{i}} \mathrm{T}_{\mathrm{k}, \mathrm{i}}\right\}$

Let $V$-Stop-Number $(\mathrm{K})$ be the optimal value of Stop-Number $(\mathrm{K})$. Then we get the Stop Number model: \{Compute $\mathrm{K}$ which minimizes $V$-Stop-Number $(\mathrm{K})$ \}

Stop Number and Graph Coloring, Remarks about Complexity: If $\mathrm{H}=0$ and $\mathrm{C}$ $=1$, any feasible solution $(\mathrm{Z}, \mathrm{T})$ of the Stop-Number problem defines a vertex coloring of the intersection graph induced by the collection $\mathrm{I}_{\mathrm{j}, 0}$ of discrete intervals of the 
Stop Node set. Still, though interval graph coloring is known to be time-polynomial [17], we conjecture that even in this case, the Stop-Number problem is NP-Hard.

If $\mathrm{H}=0$, and no hypothesis is done about $\mathrm{C}$ and the loads $\mathrm{L}(\mathrm{j}), \mathrm{j}=1 . . \mathrm{m}$, we check that Stop-Number is NP-Hard, since, if $\mathrm{K}=2$, and $\mathrm{o}(\mathrm{j})=0$ and $\mathrm{d}(\mathrm{j})=\mathrm{n}-1$ for every $\mathrm{j}=$ 1..m, then we see that Stop-Number $(\mathrm{K})$ contains the 2-Partition Problem.

If $\mathrm{K}$ and $\mathrm{C}$ are fixed, and the number $\mathrm{H}$ is part of the problem, then Stop-Number may be solved in polynomial time through dynamic programming. It can be checked by following the guidelines of the proof of Proposition 2, Section III.

Extensions and Variants: Introducing time windows in the Stop-Number model, means setting lower and upper bound $\operatorname{Min}(\mathrm{j}), \operatorname{Max}(\mathrm{j}), \mathrm{j}=1 . . \mathrm{m}$ on $\mathrm{h}(\mathrm{j})$ values means imposing: $\mathrm{Z}_{\mathrm{j}, \mathrm{k}, \mathrm{h}}=0$ for any $\mathrm{h} \notin\{\operatorname{Min}(\mathrm{j}), . ., \operatorname{Max}(\mathrm{j})\}$. Also, since we also want to commpare the Stop-Number criterion with some standard criteria, we provide here variants of the above Stop-Number model, which allow dealing with those criteria:

Vehicle-Number Minimization: \{Compute the smallest value $\mathrm{K}=\mathrm{K}_{\mathrm{Min}}$ such that Stop-Number $(\mathrm{K})$ has a feasible solution $\}$

Global-Riding Minimization: $\left\{\right.$ Compute $\mathrm{K}=\mathrm{K}_{\mathrm{Glob}}$ such that Stop-Number $(\mathrm{K})$ has a feasible solution and such that the quantity $\Sigma_{\mathrm{k}}$ Ride $_{\mathrm{k}}$ is minimal, where Ride $e_{\mathrm{k}}$ is an additional integral variable, submitted to the contraints: for any $\left.\mathrm{h}, \mathrm{j}, \mathrm{h} . \mathrm{Z}_{\mathrm{j}, \mathrm{k}, \mathrm{h}} \leq \operatorname{Ride}_{\mathrm{k}}\right\}$

Waiting-Times Minimization: $\left\{\right.$ Compute $\mathrm{K}=\mathrm{K}_{\mathrm{Wait}}$ such that Stop-Number $(\mathrm{K})$ has a feasible solution and such that the quantity $\Sigma_{\mathrm{j}} \Sigma_{\mathrm{k}, \mathrm{h}} \mathrm{h} . \mathrm{Z}_{\mathrm{j}, \mathrm{k}, \mathrm{h}}=$ is the minimal $\}$.

Remark: The waiting times criterion is antagonistic to the vehicle number one: $\mathrm{K}_{\mathrm{Wait}}$ will be such that $h(j)=0$ for any $j=1$..m.

\section{A Branch/Price Method for Stop-Number.}

The Stop-Number(K) ILP model is difficult to handle as soon as parameters n, $\mathrm{m}$, $\mathrm{H}$ and $\mathrm{K}$ do not take small values. Worse, as it also happens for Graph Coloring: [6, $8,12]$, above Stop-Number model is not a true ILP one. So, following [1, 9], we reformulate it as a column generation oriented ILP model. A feasible service is any pair $\mathrm{s}=(\mathrm{J}, \mathrm{h})$, where $\mathrm{J} \subseteq\{1 . . \mathrm{m}\}$, and $\mathrm{h}$ some function from $\{1 . . \mathrm{m}\}$ to $\{0 . . \mathrm{H}\}$, such that, for any $\mathrm{i}=0 . .(\mathrm{H}+2) . \mathrm{n}-1, \Sigma_{\mathrm{j} \in \mathrm{D} \text { such that }(\mathrm{j}, \mathrm{h}(\mathrm{j})) \in \mathrm{A}(\mathrm{i})} \mathrm{L}(\mathrm{j}) \leq \mathrm{C}$. Clearly, a feasible service identifies the demands $\mathrm{j}$ which are serviced by a same vehicle as well as related waiting times $\mathrm{h}(\mathrm{j})$. We denote by $\mathrm{S}$ the set of all feasible services. For any $\mathrm{s}=(\mathrm{J}, \mathrm{h}) \in \mathrm{S}$, we set $\operatorname{Stop}(\mathrm{s})=\{\mathrm{i} \in 1 . .(2+\mathrm{H}) . \mathrm{n}-1$, such that $\mathrm{B}(\mathrm{i}) \cap\{\mathrm{j}, \mathrm{h}(\mathrm{j}), \mathrm{j}=1 . . \mathrm{m}) \neq \mathrm{Nil}\}$, and $N$ $\operatorname{Stop}(\mathrm{s})=\operatorname{Card}(\operatorname{Stop}(\mathrm{s}))$. Then we reformulate Stop-Number problem as follows:

\section{Stop-Number Reformulation:}

$\left\{\right.$ Compute: $\left(\mathrm{X}_{\mathrm{s}}, \mathrm{s} \in \mathrm{S}\right)$ with $\{0,1\}$ values: $\mathrm{X}_{\mathrm{s}}=1$ if some vehicle performs the feasible service $\mathrm{s}$.

Constraints : For any $\mathrm{j} \in 1 . . \mathrm{m}, \Sigma_{\mathrm{s} \text { such that } \mathrm{j} \in \mathrm{s}} \mathrm{X}_{\mathrm{s}}=1 ;(*$ every demand is met*) 


\section{Minimize : $\sum_{\mathrm{s}} N$-Stop $\left.(\mathrm{s}) . \mathrm{X}_{\mathrm{s}}\right\}$}

Then we may also rewrite the Vehicle-Number problem: $\{$ Compute $\mathrm{K}=$ minimal number of vehicles and $\left(X_{s}, s \in S\right)$ with $\{0,1\}$ values such that:

- For any $\mathrm{j} \in 1 . . \mathrm{m}, \Sigma_{\mathrm{s} \text { such that } \mathrm{j} \in \mathrm{s}} \mathrm{X}_{\mathrm{s}}=1$; (*Every demand is serviced once*)

- $\quad \Sigma_{\mathrm{s}} \mathrm{X}_{\mathrm{s}} \leq \mathrm{K} ; \quad$ (*Vehicle number no more than $\left.\left.\mathrm{K} *\right)\right\}$

By the same way, we notice that, with any service $s=(J, h)$ we may associate:

- $\quad$ its Waiting Number $N$-Wait(s) $=\Sigma_{\mathrm{j} \in \mathrm{J}} \mathrm{h}(\mathrm{j})$

- $\quad$ Its Global Ride Number N-Glob(s) $=\operatorname{Sup}_{\mathrm{j} \in \mathrm{J}} \mathrm{h}(\mathrm{j})$

So, we may also rewrite the Global-Riding and Waiting-Times variants by replacing, inside the Stop-Number reformulation, the "Minimize $: \Sigma_{\mathrm{s}} N$-Stop(s).X ${ }_{\mathrm{s}}$ " criterion by, respectively, "Minimize : $\Sigma_{\mathrm{s}} N$-Glob(s).X. $\mathrm{X}_{\mathrm{s}}$ " and "Minimize $: \Sigma_{\mathrm{s}} N$-Wait(s).X $\mathrm{X}_{\mathrm{s}}$ ". Methods for the Stop-Number Problem will also work for those problems.

We are now going to describe the Branch/Price procedure, close to clustering algorithms of [1] and [13], which will be implemented with the help of the SCIIP library ([14]). In order to do it, we first specify the way tree search, bounding, branching, and constraint propagation are performed. Next we shall address the Pricing issue.

Tree Search: A node $\mathcal{N}$ in the search tree induced by the Stop-Number process will be defined by a collection of additional constraints $\operatorname{EX}\left(\mathrm{j}_{1}, \mathrm{j}_{2}\right), \operatorname{IN}\left(\mathrm{j}_{1}, \mathrm{j}_{2}\right), \operatorname{WAIT}^{+}(\mathrm{j}, \mathrm{h})$, $\operatorname{WAIT}^{-}(\mathrm{j}, \mathrm{h})$, whose meaning comes as follows:

- $E X\left(j_{1}, j_{2}\right):$ demands $j_{1}, j_{2}$ are handled by the same vehicle;

- $\quad I N\left(j_{1}, j_{2}\right): j_{1}$ and $j_{2}$ cannot belong to the same service $s$;

- $\operatorname{WAIT}^{+}(\mathrm{j}, \mathrm{h})\left(\operatorname{WAIT}^{-}(\mathrm{j}, \mathrm{h})\right)$ : the waiting time of $\mathrm{j}$ must not be smaller (larger) than $h$; WAIT constraints restrict the set $\mathrm{H}(\mathrm{j})$ of possible $\mathrm{h}(\mathrm{j})$ values.

Lower Bound/Branching: We insert (E1) into the Stop-Number ILP by setting:

- In case of a $E X\left(j_{1}, j_{2}\right)$ constraint: $X_{s}=0$ for any s containing both $j_{1}$ and $j_{2}$; (E2)

- In case of $\operatorname{aIN}\left(\mathrm{j}_{1}, \mathrm{j}_{2}\right)$ constraint: $X_{\mathrm{s}}=0$ for any s which contains $\mathrm{j}_{1}$ and not $\mathrm{j}_{2}$, and for any $s$ which contains $\mathrm{j}_{2}$ and not $\mathrm{j}_{1}$;

- In case of a $\operatorname{WAIT}^{+}(j, h)\left(\operatorname{WAIT}^{-}(j, h)\right)$ constraint: $X_{s}=0$ for any s which contains $j$ with a waiting time less (more) than $\mathrm{h}$;

Let us denote by Stop-Number-Aux(EX, IN, WAIT) the resulting ILP. The optimal value of its integral relaxation Stop-Number-Aux(EX, IN, WAIT)* provides us with a lower bound for $\mathcal{N}$. X being some related solution, we get, as in [13]:

Proposition 1. If $X$ is not integral, then there must:

- either exist $\mathrm{j}_{1}$ and $\mathrm{j}_{2}$ in $\{1 . . \mathrm{m}\}$ such that:

- there exist $s$, such that $X \neq 0$ and not integral, which contains both $\mathrm{j}_{1}$ and $\mathrm{j}_{2}$;

- there exist s', such that $X \neq 0$ and not integral, which contains $j_{1}$ and not $j_{2}$;

- $\quad$ or $\mathrm{j}, \mathrm{s}_{1}$ and $\mathrm{s}_{2}$ such that:

- $\quad$ both $\mathrm{X}_{\mathrm{s} 1}$ and $\mathrm{X}_{\mathrm{s} 2}$ are non null and not integral; 
- the waiting times $h_{1}(j)$ and $h_{2}(j)$ of $j$ in $s_{1}$ and $s_{2}$ are different.

Proof: as in [13]: for any pair $\left(\mathrm{j}_{1}, \mathrm{j}_{2}\right), \mathrm{j}_{1} \neq \mathrm{j}_{2}$, such that there is no constraint $\operatorname{EX}\left(\mathrm{j}_{1}\right.$, $\left.\mathrm{j}_{2}\right)$, we denote by $\alpha\left(\mathrm{j}_{1}, \mathrm{j}_{2}\right)$ the sum $\alpha\left(\mathrm{j}_{1}, \mathrm{j}_{2}\right)=\Sigma_{\mathrm{j} 1, \mathrm{j} 2 \in \mathrm{s}} \mathrm{X}_{\mathrm{s}}$. In case some value $\alpha\left(\mathrm{j}_{1}, \mathrm{j}_{2}\right)$ is non integral, we are done. Else, the pairs $\left(\mathrm{j}_{1}, \mathrm{j}_{2}\right)$ such that $\alpha\left(\mathrm{j}_{1}, \mathrm{j}_{2}\right)=1$ define a non oriented graph whose connected components are complete sub-graphs and induce a partition $\mathrm{D}_{1} \cup . . \cup \mathrm{D}_{\mathrm{P}}$ of the set $\{1 . . \mathrm{m}\}$. If any $\mathrm{j} \in \mathrm{D}_{\mathrm{p}}$ always appear in related services with the same waiting times, then only one service $\mathrm{s}=\mathrm{s}(\mathrm{p})$ such that $\mathrm{X}_{\mathrm{s}} \neq 0$ may be considered as associated with $\mathrm{D}_{\mathrm{p}}$, and $\mathrm{X}$ is a feasible integral solution of StopNumber-Aux(EX, IN, WAIT). Else we get the (E7) pattern. END-PROOF.

Then we pick up $\left(\mathrm{j}_{1}, \mathrm{j}_{2}\right)$ which satisfies (E6) and branch between $\operatorname{EX}\left(\mathrm{j}_{1}, \mathrm{j}_{2}\right)$ and $\operatorname{IN}\left(\mathrm{j}_{1}, \mathrm{j}_{2}\right)$, and, in case of failure, pick up $\mathrm{j}, \mathrm{s}_{1}$ and $\mathrm{s}_{2}$ such that (E7) holds, and such that $\mathrm{h}_{1}(\mathrm{j})<\mathrm{h}_{2}(\mathrm{j})$, and branch between $\operatorname{WAIT}^{-}\left(\mathrm{j}, \mathrm{h}_{2}(\mathrm{j})\right)$ and $\mathrm{WAIT}^{+}(\mathrm{j}, \mathrm{h})$. In case (E6) pattern may be used, we choose $j_{1}, j_{2}$, in such a way the sum of their degrees in the union of IN and EX graphs is the largest possible (most constrained variable principle). In case only (E7) may be used, we choose $\mathrm{j}$ which maximizes area $(\mathrm{L}(\mathrm{j}) .(\mathrm{d}(\mathrm{j})-\mathrm{o}(\mathrm{j}))$.

Constraint Propagation: Given a node $\mathcal{N}$ of the Search Tree induced by the StopNumber process. We derive constraint propagation inference rules by noticing that: any connected component of the IN graph should define a complete sub-graph; the EX relation should be extended to those connected components; if $\mathrm{G}_{1}$ is some connected component of the IN graph and if no insertion of $j$ into $G_{1}$ is possible without violating either the WAIT constraints or the Capacity constraint, then we should have $\operatorname{EX}\left(j_{1}, G_{1}\right)$; if only 1 value $h$ exists in $H(j)$, then $h(j)$ should be equal to $h$.

\section{A. Handling the integral relaxation of Stop-Number-Aux(EX, IN, WAIT).}

We do it through column generation. Given $\mathrm{S}_{0} \subseteq \mathrm{S}$, the restriction Stop-Number$\operatorname{Aux}(\mathrm{EX}, \mathrm{IN}, \mathrm{WAIT})_{\mathrm{S} 0}$ to $\mathrm{S}_{0}$ of the integral relaxation of Stop-Number-Aux (EX, IN, WAIT $)$ and $\left(\lambda=\left(\lambda_{\mathrm{j}}, \mathrm{j}=1 . . \mathrm{m}\right)\right)$ a related dual solution. Then, Pricing comes as follows:

\section{ILP Stop-Number-Price Model:}

\section{$\{$ Compute:}

$\circ \mathrm{Z}=\left(\mathrm{Z}_{\mathrm{j}, \mathrm{h}}, \mathrm{j}=1 . . \mathrm{m}, \mathrm{h}=0 . . \mathrm{H}\right)$ with $\{0,1\}$ values $: \mathrm{Z}_{\mathrm{j}, \mathrm{h}}=1$ if $(\mathrm{j}, \mathrm{h})$ is in $\mathrm{s}$;

○ $\mathrm{T}=\left(\mathrm{T}_{\mathrm{i}} \mathrm{i}=1 . .(2+\mathrm{H}) \mathrm{n}-1\right.$, with $\{0,1\}$ values $: \mathrm{T}_{\mathrm{i}}=1$ if $\mathrm{i} \in \mathrm{Stop}(\mathrm{s})$.

Constraints :

$$
\begin{array}{ll}
\circ & \forall \mathrm{i}=0 . .(2+\mathrm{H}) \cdot \mathrm{n}-1: \Sigma_{(\mathrm{j}, \mathrm{h}) \in \mathrm{A}(\mathrm{i})} \mathrm{L}(\mathrm{j}) . \mathrm{Z}_{\mathrm{j}, \mathrm{h}} \leq \mathrm{C} ; \\
\circ & \forall \mathrm{j}=1 . . \mathrm{m}, \Sigma_{\mathrm{h}=0 . \mathrm{H}} \mathrm{Z}_{\mathrm{j}, \mathrm{h}} \leq 1 ;\left(* \text { No Redundancy Constraint }{ }^{*}\right) \\
\circ & \forall \mathrm{i}=1 . .(2+\mathrm{H}) . \mathrm{n}-1,(\mathrm{j}, \mathrm{h}) \text { in } \mathrm{B}(\mathrm{i}): \mathrm{Z}_{\mathrm{j}, \mathrm{h}} \leq \mathrm{T}_{\mathrm{i}} ; \quad\left({ }^{2} \text { Coupling Constraints } *\right) \\
\circ & \forall\left(\mathrm{j}_{1}, \mathrm{j}_{2}\right) \text { in EX, } \mathrm{Z}_{\mathrm{j} 1}+\mathrm{Z}_{\mathrm{j} 2} \leq 1 ; \forall\left(\mathrm{j}_{1}, \mathrm{j}_{2}\right) \text { in IN, } \mathrm{Z}_{\mathrm{j} 1}=\mathrm{Z}_{\mathrm{j} 2} ; \\
\circ & \forall(\mathrm{j}, \mathrm{h}) \text { in } \mathrm{WAIT}^{+}\left(\text {WAIT }^{-}\right), \text {for any } \mathrm{h}^{\prime}<\mathrm{h}\left(\mathrm{h}^{\prime}>\mathrm{h}\right), \mathrm{Z}_{\mathrm{j}, \mathrm{h}}=0 ;
\end{array}
$$


Maximize : $\Sigma_{\mathrm{j}} \lambda_{\mathrm{j}} \cdot \mathrm{Z}_{\mathrm{j}, \mathrm{h}}-\Sigma_{\mathrm{i}} \mathrm{T}_{\mathrm{i}}$, which should $\left.>0\right\}$.

We conjecture that this problem is NP-Complete. Still, we may notice that:

Proposition 2: If C is fixed, then Stop-Number-Price is time-polynomial.

Proof. It can be solved as a largest path problem set on an acyclic digraph $\mathrm{F}$ with a number of vertices which depends in a polynomial way on $\mathrm{n}$ and $\mathrm{H}$. We first define a state as being any integer valued vector $\mathrm{V}=\left(\mathrm{V}_{1}, . ., \mathrm{V}_{\mathrm{C}}\right)$, such that $\mathrm{n} \geq \mathrm{V}_{1} \geq \mathrm{V}_{2} \geq . . \geq \mathrm{V}_{\mathrm{C}}$ $\geq-1$ : the vehicle is loaded with $L \geq c$ when arriving to any $i_{1}$ such that $i_{1} \leq i+V_{c}$ and this $L$ is less than $c$ when the vehicle leaves node $i+V_{c} ; V_{1}=-1$ means that the vehicle is empty when it arrives to i. Clearly, V tells us whether the vehicle unloads or loads at $i$, and, so, whether $i$ is currently a stop node for s. We denote by SV the set of all possible states. Then nodes in the digraph $F$ are 3 -uples $(i, j, V), i \in I(\Gamma), j=1 . . m$, such that $\mathrm{o}(\mathrm{j})=\mathrm{i}$ modulo $\mathrm{n}, \mathrm{V} \in \mathrm{SV}$, augmented with fictitious nodes Start and End. An arc $\left(\left(i_{0}, j_{0}, V_{0}\right),\left(i_{1}, j_{1}, V_{1}\right)\right)$ exists in $F$ if one of the following conditions holds:

- $\quad \mathrm{i}_{1}=\mathrm{i}_{0}+1, \mathrm{j}_{1}=$ (smallest value $\mathrm{j}$, such that $\mathrm{o}(\mathrm{j})=\mathrm{i}_{1}$ modulo $\left.\mathrm{n}\right), \mathrm{V}_{1}=\mathrm{V}_{0}-1$;

- $\mathrm{i}_{1}=\mathrm{i}_{0}, \mathrm{j}_{1}=\left(\right.$ smallest value $\mathrm{j}>\mathrm{j}_{0}$, such that $\mathrm{o}(\mathrm{j})=\mathrm{i}_{1}$ modulo $\left.\mathrm{n}\right), \mathrm{V}_{1}=\mathrm{V}_{0}$;

- $\mathrm{i}_{1}=\mathrm{i}_{0}, \mathrm{j}_{1}=$ (smallest value $\mathrm{j}>\mathrm{j}_{0}$, such that $\mathrm{o}(\mathrm{j})=\mathrm{i}_{1}$ modulo $\mathrm{n}$ ), $\mathrm{V}_{1}$ derives from

$\mathrm{V}_{0}$ by adding load $\mathrm{L}\left(\mathrm{j}_{0}\right)$ between $\mathrm{i}_{0}$ and $\mathrm{i}_{0}+\mathrm{d}\left(\mathrm{j}_{0}\right)-\mathrm{o}\left(\mathrm{j}_{0}\right)$.

In the first 2 cases, the arc $\left(\left(i_{0}, j_{0}, V_{0}\right),\left(i_{1}, j_{1}, V_{1}\right)\right)$ has a null length. In the third case, it is provided with a length which expresses the impact on the Stop Number of the insertion of $\mathrm{j}_{0}$ into $\mathrm{s}$, taking into account current state $\mathrm{V}_{0}$. One easily checks that solving Stop-Number-Price means computing a largest path in F. END-PROOF.

Still, proposition 2 is hardly suitable for application, since Card(SV) increases as $\mathrm{n}^{\mathrm{C}}$. So, in order to deal with the Stop-Number-Price issue in an efficient way, we adopt a double trigger approach: we first try a fast GRASP insertion/removal process, and, in case of failure, we try an exact method involving a flow reformulation.

The Initialization of the GRASP process works by successive insertions of connected components $\mathrm{G}$ of the IN graph into a current feasible service s, until $\Sigma_{\mathrm{j} \in \mathrm{s}} \lambda_{\mathrm{j}}-$ $N$-Stop(s)) $>0$ or no additional insertion is possible, while considering that the largest are $\lambda_{j}$ and $\operatorname{Card}(H(j))$, and the smallest are $L(j), d(j)-o(j)$ and the number of induced additional stop nodes, the most relevant is inserting $\mathrm{j}$ into s; its Local Search loop works as a descent process involving operators $\operatorname{Remove}(\mathrm{G})$ : demands $\mathrm{j} \in \mathrm{G}$ are removed from s; Insert $(\mathrm{G})$ : demands $\mathrm{j} \in \mathrm{G}$, are inserted into s; Exchange $\left(\mathrm{G}_{1}, \mathrm{G}_{2}\right)$ : performs Remove $\left(\mathrm{G}_{1}\right)$ and next $\operatorname{Insert}\left(\mathrm{G}_{2}\right) ; \operatorname{Move}(\mathrm{j}, \mathrm{h})$ : the waiting time of $\mathrm{j} \in \mathrm{s}$ demand $\mathrm{j}$ is re-assigned to $h$, where $G, G_{1}$ and $G_{2}$ are connected components of the IN graph.

\section{B. Handling Stop-Number-Price through a Max Flow and Lagrangean Relaxation.}

Let us introduce the Demand Network D-NET, whose node set is the set $\{0 . .(2+\mathrm{H}) . \mathrm{n}-1\}$ and whose arcs are: 
○ demand arcs $\mathrm{a}_{\mathrm{j}, \mathrm{h}}=(\mathrm{o}(\mathrm{j})+\mathrm{h}, \mathrm{d}(\mathrm{j})+\mathrm{h}), \mathrm{j}=1 . . \mathrm{m}, \mathrm{h}=0 . . \mathrm{H}$, provided with a null lower capacity $\operatorname{Min}\left(a_{j}\right)$, an upper capacity $\operatorname{Max}\left(a_{j}\right)=L(j)$, and a cost $Q\left(a_{j}\right)=\lambda_{j}$;

○ chain $\operatorname{arcs} \mathrm{e}_{\mathrm{i}}=(\mathrm{i}, \mathrm{i}+1), \mathrm{i}=0 . .(2+\mathrm{H}) \cdot \mathrm{n}-2 ; \operatorname{Min}\left(\mathrm{e}_{\mathrm{i}}\right)=0, \operatorname{Max}\left(\mathrm{e}_{\mathrm{i}}\right)=+\infty, \mathrm{Q}\left(\mathrm{e}_{\mathrm{i}}\right)=0$;

○ a backward $\operatorname{arc} b k=((2+\mathrm{H}) \cdot \mathrm{n}-1,0) ; \operatorname{Min}(b k)=\operatorname{Max}(b k)=\mathrm{C}, \mathrm{Q}(b k)=0$.

This allows us to reformulate Stop-Number-Price as the following flow problem:

\section{Flow Stop-Number-Price Formulation.}

\{Compute on the network D-NET an integral flow vector F, together with $2\{0$, 1 )-valued vector $\mathrm{T}=\left(\mathrm{T}_{\mathrm{i}}, \mathrm{i}=1 . .(2+\mathrm{H}) . \mathrm{n}-1\right)$ and $\mathrm{U}=\left(\mathrm{U}_{\mathrm{j}}, \mathrm{j}=1 . . \mathrm{m}\right)$, such that:

○ $\mathrm{F}$ is consistent with Min/Max capacities ;

○ For any demand $\operatorname{arc} \mathrm{a}_{\mathrm{j}, \mathrm{h}}, \mathrm{F}_{\mathrm{aj}, \mathrm{h}}=0$ or L(j); (E9: Non Load Preemption)

$\circ \quad$ For any $h$ in $\{0 . . m\}-H(j), F_{a j, h}=0$;

For any $\mathrm{j}=1 . . \mathrm{m}, \mathrm{L}(\mathrm{j}) \cdot \mathrm{U}_{\mathrm{j}}=\Sigma_{\mathrm{h}} \mathrm{F}_{\mathrm{aj}, \mathrm{h}}$;

(E11: No Redundancy)

For any pair $\left(\mathrm{j}_{1}, \mathrm{j}_{2}\right) \in \mathrm{EX}: \mathrm{U}_{\mathrm{j} 1}+\mathrm{U}_{\mathrm{j} 2} \leq 1$;

For any pair $\left(\mathrm{j}_{1}, \mathrm{j}_{2}\right) \in \mathrm{IN}: \mathrm{U}_{\mathrm{j} 1}-\mathrm{U}_{\mathrm{j} 2}=0$;

For any $\mathrm{i}=1$.. $(2+\mathrm{H}) \mathrm{n}-1, \mathrm{j} \in \mathrm{B}(\mathrm{i}): \mathrm{U}_{\mathrm{j}} \leq \mathrm{T}_{\mathrm{i}}$;

Maximize $\Sigma_{\mathrm{j}, \mathrm{h}} \lambda_{\mathrm{j}} \cdot \mathrm{F}_{\mathrm{j}, \mathrm{h}}-1 . \mathrm{T}$, which should be $\left.>0\right\}$.

We relax (E9) and consider the Lagrangean relaxation of (E11). Given multipliers $\mu=\left(\mu_{\mathrm{j}}, \mathrm{j}=1 . . \mathrm{m}\right)$ we set: $\mathrm{L}(\mathrm{F}, \mathrm{T}, \mathrm{U}, \mu)=\lambda . \mathrm{F}-1 . \mathrm{T}-\Sigma_{\mathrm{j}} \mu_{\mathrm{j} .}\left(\mathrm{L}(\mathrm{j}) \cdot \mathrm{U}_{\mathrm{j}}-\Sigma_{\mathrm{h}} \mathrm{F}_{\mathrm{aj}, \mathrm{h}}\right)$. Maximizing $\mathrm{L}(\mathrm{F}, \mathrm{T}, \mathrm{U}, \mu)$ may be done by solving 2 independent sub-problems:

- A Max Flow problem about F: \{Compute an integral flow vector F, consistent with capacity and (E10) constraints, and maximizing: $\left.\Sigma_{\mathrm{j}, \mathrm{h}}\left(\lambda_{\mathrm{j}}+\mu_{\mathrm{j}}\right) . \mathrm{F}_{\mathrm{aj}, \mathrm{h}}\right\}$.

- A problem $\boldsymbol{P}$-A $\boldsymbol{A} \boldsymbol{x}$ about $\mathrm{U}$ and $\mathrm{T}$ : $\left\{\right.$ Compute $\mathrm{T}=\left(\mathrm{T}_{\mathrm{i}}, \mathrm{i}=1 . .(2+\mathrm{H}) \mathrm{n}-1\right)$ and $\mathrm{U}=$ $\left(\mathrm{U}_{\mathrm{j}}, \mathrm{j}=1 . . \mathrm{m}\right)$, with $\{0,1\}$ values, which satisfy $(\mathrm{E} 12, \mathrm{E} 13, \mathrm{E} 14)$ and which minimize $1 . T+\Sigma_{\mathrm{j}} \mu_{\mathrm{j}} \mathrm{L}(\mathrm{j}) \cdot \mathrm{U}_{\mathrm{j}}$. If C-IN is the set of connected components of the IN graph, then we may extend to $\mathrm{C}$-IN the EX exclusion in a natural way, and replace $\mathrm{U}$ by a C-IN indexed vector $\mathrm{U}^{*}$, subject to:

(Reduced-P-Aux)

○ $\forall \mathrm{c}_{1}, \mathrm{c}_{2} \in \mathrm{C}$-IN such that $\mathrm{EX}\left(\mathrm{c}_{1}, \mathrm{c}_{2}\right), \mathrm{U}^{*}{ }_{\mathrm{c} 1}+\mathrm{U}^{*}{ }_{\mathrm{c} 2} \leq 1$;

○ $\forall \mathrm{c} \in \mathrm{C}-\mathrm{IN}, \mathrm{i}=1 . .(2+\mathrm{H}) . \mathrm{n}-1$, such that $\mathrm{B}(\mathrm{i}) \cap \mathrm{c} \neq \mathrm{Nil}, \mathrm{U}^{*}{ }_{\mathrm{c}} \leq \mathrm{T}_{\mathrm{i}}$; (E16)

$\circ \quad$ The quantity1.T $+\Sigma_{\mathrm{c}}\left(\Sigma_{\mathrm{j} \in \mathrm{c}} \mu_{\mathrm{j}} . \mathrm{L}(\mathrm{j})\right) . \mathrm{U}{ }^{*}{ }_{\mathrm{c}}$ is minimal.

We see that (E15) impose $\mathrm{U}^{*}$ to define an independent subset of the graph $(\mathrm{C}$ IN, EX) defined on C-IN by the EX relation. This graph usually happens to be a sparse graph, with few edges, whose cliques and odd cycles with no chords may easily be enumerated. So constraints (E15) may be replaced by stronger constraints, which are usually facets of the Independent Set polytope (see $[2,9,15])$ :

$\circ$ For any clique $\mathrm{Q}$ in the graph $(\mathrm{C}-\mathrm{IN}, \mathrm{EX}), \Sigma_{\mathrm{c} \in \mathrm{Q}} \mathrm{U}^{*}{ }_{\mathrm{c}} \leq 1 ; \quad(\mathrm{E} 15-1)$

$\circ$ For any odd cycle $\Lambda$ with no chord in the graph $(\mathrm{C}-\mathrm{IN}, \mathrm{EX}), \Sigma_{\mathrm{c} \in \Lambda} \mathrm{U}_{\mathrm{c}} \leq$ $\lfloor\operatorname{Card}(\Lambda) / 2\rfloor$.

$(\mathrm{E} 15-2)$ 
This makes possible, in most cases, solving Reduced-P-Aux, through a simple relaxation of the integrality constraint followed by a simple rounding process.

Proposition 3: The Non Load Preemption Constraint (E9) contains the integrality constraints on $\mathrm{F}, \mathrm{U}$ and $\mathrm{T}$. That means that if $\mathrm{F}, \mathrm{U}, \mathrm{T}$ are rational vectors which satisfy (E8..E14) then they are integral.

Proof: left to the reader. END-PROOF.

As a consequence, we handle Stop-Number-Price through Branch and Bound:

- Bounding derives from computing the Lagrangean value Min ${ }_{\mu}$ Max F, T, U satisfy (E8, E10, E15-1, E15-2, E16) $\mathrm{L}(\mathrm{F}, \mathrm{T}, \mathrm{U}, \mu)$. This process yields some triple F, T, U.

- Branching is performed according to a 3 trigger mechanism:

- If $\mathrm{F}$ resulting from bounding does not satisfy (E9), then we pick up $\mathrm{a}_{\mathrm{j}, \mathrm{h}}$ such that $\mathrm{F}_{\mathrm{aj}, \mathrm{h}} \neq 0$ and $\mathrm{F}_{\mathrm{aj}, \mathrm{h}} \neq 0 \mathrm{~L}(\mathrm{j})$, and try both $\mathrm{F}_{\mathrm{aj}, \mathrm{h}}=0$ and $\mathrm{F}_{\mathrm{aj}, \mathrm{h}}=\mathrm{L}(\mathrm{j})$.

$\circ \quad$ In case $F$, U satisfy (E9) and j, h, h' exist such that $F_{a j, h}=F_{a j, h}=L(j)$, then we pick up j, h such that $F_{a j, h}=L(j)$ and try both $F_{a j, h}=0$ and $F_{a j, h}=L(j)$;

$\circ \quad$ Else we pick up $\mathrm{j}$ such that $\mathrm{U}_{\mathrm{j}}=1$ and $\Sigma_{\mathrm{h}} \mathrm{F}_{\mathrm{aj}, \mathrm{h}}=0$, and branch between $\mathrm{U}_{\mathrm{j}}=0$, and the $\mathrm{h}+1$ options $\mathrm{F}_{\mathrm{aj}, \mathrm{h}}=1, \mathrm{~h}=0 . . \mathrm{H}$.

\section{$4 \quad$ An Insertion Method}

Since our ultimate goal is the real time VIPA management, we also propose an insertion algorithm Stop-Number-Insert: demands are successively inserted into the vehicles. Such an algorithm links in a well-fitted way off line and on line paradigms: when dealing with an on line instances, we insert, in real time, recent demands into the currently working vehicles. Those usually non deterministic algorithms may be cast into Monte-Carlo schemes. We do not detail here the way Stop-Number-Insert works, and restrict ourselves to a brief description of its general structure:

\section{Stop-Number-Insert Algorithmic Scheme:}

$\mathrm{J}<-\{1 . . \mathrm{m}\} ; \mathrm{K} ; \operatorname{Service}(1)<-\mathrm{Nil} ;\left({ }^{*} \operatorname{Service}(\mathrm{k}), \mathrm{k}=1 . . \mathrm{K}\right.$, is the current service of vehicle k; $\mathrm{K}$ denotes a Fictitious Vehicle, and $\mathrm{K}-1$ is the Vehicle Number*)

While $\mathrm{J} \neq$ Nil do

Randomly pick up $\mathrm{j}_{0} \in \mathrm{J}$, according to some priority rules;

Compute $\mathrm{k}_{0}$ in $1 . . \mathrm{K}, \mathrm{h}_{0}=0 . . \mathrm{H}$, such that the insertion of $\mathrm{j}_{0}$ into Service $\left(\mathrm{k}_{0}\right)$ with waiting time value $h\left(\mathrm{j}_{0}\right)=\mathrm{h}_{0}$ is feasible and its Quality level is the highest possible; Insert $\left(\mathrm{j}_{0}, \mathrm{~h}_{0}\right)$ into Service $\left(\mathrm{k}_{0}\right)$ and remove $\mathrm{j}_{0}$ from $\mathrm{J}$; (I2) If $\mathrm{k}_{0}=\mathrm{K}$ then increase $\mathrm{K}$ by 1 ;

Stop-Number-Insert <- (Vehicle Number $\mathrm{K}-1$, Service $(\mathrm{k}), \mathrm{k}=1 . . \mathrm{K}-1)$. 
Since Stop-Number-Insert is non deterministic, it may be cast into the following Monte-Carlo scheme, which involves a replication parameter R:

For i $=1 . . \mathrm{R}$ do Apply Stop-Number-Insert;

Keep the best solution (Service, K-1) ever obtained.

Priority Rules (Instruction (I1)) lead to deal with those among the remaining demands which appear to be the most difficult to insert. Quality criteria lead us to choose $\mathrm{k}_{0}$ and $\mathrm{h}_{0}$ in such a way the fewest possible additional stop nodes are created and current stop nodes may be reused as often as possible.

\section{$5 \quad$ Numerical Tests}

We present here tests, which are performed on a LINUX server CentOS 5.4, Quadripro Quadcore, $3 \mathrm{Ghz}$. In order to deal with ILP models, we use the SCIIP freeaccess software (see [14]), combined with CPLEX12 LP Library, which efficiently implements the branch/cut/price generic framework. Since no test-bed exists for the Stop-Number problem, we randomly generate instances, whose characteristics are:

- $\quad n=$ number of stop nodes of the circuit; $m=$ number of demands;

- $\quad n$-act $=$ number of active nodes; $w=$ mean load value;

- $\quad C=$ capacity of the vehicles; $t=$ mean distance between $o(j)$ and $d(j), j=1 . . m$;

- $\quad \mathrm{H}=$ maximum authorized waiting time.

For every such an instance, we try the Stop-Number ILP model of Section II, solved by CPLEX12, the column generation oriented reformulation of Stop-Number of Section III, and the Stop-Number-Insert algorithm of Section IV.

While performing this experiment, we want to evaluate the algorithms, and compare the Vehicle Number and Global Riding Time values which derive from the StopNumber process with their optimal values. So, for every instance, we denote by:

- $\quad \mathrm{K}_{\mathrm{Mi}}$ the optimal Vehicle Number, and Stop p $_{0}$ the related Stop Number;

- $\quad \mathrm{St}_{\mathrm{Min}}$ the optimal Stop Number, $\mathrm{K}_{1}$, Ride $_{1}$, the related Vehicle and Global Riding numbers; CPU is the running time of the Stop-Number program while Col and $N d$ are respectively the numbers of columns and nodes generated by the process;

- $\quad$ Ride the optimal Global Riding Time, and $\mathrm{K}_{\mathrm{G}}$ the related Vehicle Numbers.

- $\quad$ LB the lower bound induced of Section III

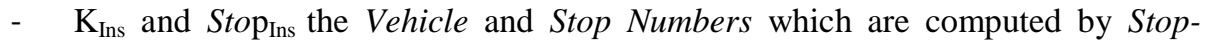
Number-Insert: $\mathrm{R}$ is the replication number, and $\mathrm{CPU}_{\mathrm{Ins}}$ the related CPU time (s). We provide here results for a 7 instance set, generated as told above:

\begin{tabular}{|l|l|l|l|l|l|l|l|}
\hline Id = Instance & $\mathbf{n}$ & $\mathbf{m}$ & $\mathbf{n - a c t}$ & $\mathbf{H}$ & $\mathbf{w}$ & $\mathbf{t}$ & $\mathbf{C}$ \\
\hline 1 & 10 & 40 & 10 & 0 & 1 & 5 & 6 \\
\hline 2 & 5 & 40 & 5 & 1 & 1 & 2.5 & 6 \\
\hline 4 & 10 & 40 & 10 & 1 & 1 & 5 & 6 \\
\hline
\end{tabular}




\begin{tabular}{|l|l|l|l|l|l|l|l|}
\hline 6 & 30 & 120 & 30 & 3 & 3 & 15 & 10 \\
\hline 7 & 30 & 70 & 28 & 4 & 5 & 15 & 10 \\
\hline 8 & 40 & 150 & 40 & 2 & 1 & 20 & 6 \\
\hline 10 & 100 & 100 & 89 & 4 & 5 & 50 & 10 \\
\hline
\end{tabular}

Table 1: Description of the instances.

\begin{tabular}{|l|l|l|l|l|l|l|}
\hline Id & $\mathbf{K}_{\mathbf{1}}$ & $\mathbf{S t}_{\text {Min }}$ & $\mathbf{C P U}$ & $\mathbf{N d}$ & $\mathbf{C o l}$ & $\mathbf{L B}$ \\
\hline 1 & 4 & 26 & 37 & 24 & 352 & 25 \\
\hline 2 & 4 & 13 & 72 & 9 & 751 & 13 \\
\hline 4 & 2 & 17 & 3 & 1 & 84 & 17 \\
\hline 6 & 30 & 120 & 30 & 3 & 3 & 15 \\
\hline 7 & 6 & 86 & 186 & 14 & 356 & 79 \\
\hline 8 & 4 & 181 & 954 & 16 & 965 & 178 \\
\hline 10 & 10 & 146 & 11986 & 24 & 9896 & 139 \\
\hline
\end{tabular}

Table 2: Behaviour of the Stop-Number Process of Section III.

\begin{tabular}{|l|l|c|l|l|l|}
\hline Id & $\begin{array}{l}\mathrm{K}_{\mathrm{INS}} \\
\mathrm{R}=1\end{array}$ & $\begin{array}{l}\text { Stop } \\
\mathrm{R}=1\end{array}$ & $\begin{array}{l}\mathrm{CPU}_{\mathrm{INS}} \\
\mathrm{R}=1\end{array}$ & $\begin{array}{l}\mathrm{K}_{\mathrm{INS}} \\
\mathrm{R}=20\end{array}$ & $\begin{array}{l}\text { Stop } \\
\mathrm{R} \text { INS }\end{array}$ \\
$\mathrm{R}=20$
\end{tabular}

Table 3: Behavior of MC-Stop-Number-Insert.

\begin{tabular}{|l|l|l|}
\hline Instance & K & CPU (s) \\
\hline 1 & 4 & 3 \\
\hline 2 & 4 & 74 \\
\hline 4 & 2 & 561 \\
\hline 6 & No Result & $*$ \\
\hline
\end{tabular}

Table 4: CPLEX12 Resolution of the Stop-Number(K) model of Section II

\begin{tabular}{|l|l|l|l|l|l|}
\hline $\mathbf{I d}$ & $\mathbf{K}_{\mathbf{M i}}$ & Stop $_{\mathbf{0}}$ & Ride & $\mathbf{K}_{\mathbf{G}}$ & Ride $_{\mathbf{1}}$ \\
\hline 1 & 4 & 26 & 0 & 4 & 0 \\
\hline 2 & 4 & 13 & 3 & 4 & 4 \\
\hline 4 & 2 & 17 & 2 & 2 & 2 \\
\hline 6 & 30 & 120 & 30 & 3 & 3 \\
\hline 7 & 5 & 89 & 18 & 5 & 20 \\
\hline
\end{tabular}




\begin{tabular}{|l|l|l|l|l|l|}
\hline 8 & 4 & 181 & 7 & 4 & 7 \\
\hline 10 & 8 & 158 & 30 & 9 & 33 \\
\hline
\end{tabular}

Table 5: Feature Analysis.

Comments: The lower bound provided by the linear relaxation of the column generation oriented reformulation of Stop-Number is very good. Still, running times remain high, since even when this lower bound happens to be equal to the optimal value of the problem, the linear relaxation of the linear program Stop-Number-Aux may not yield an integral optimal solution. Also, we notice that Stop-Number-Insert, which should efficiently perform in a dynamic context, tends to require fewer vehicles than the exact method, and that optimizing the Vehicle Number also tend to minimize the Vehicle Number, as well as the Global Riding Time. Finally we may also notice that unit load instances are easier to handle than instances when the Non Load Preemption Constraint plays an important role, and, by the same way, that forbidding waiting times, which means assuming $\mathrm{H}=0$, also tends to make the problem easier to handle.

\section{REFERENCES}

[1]. R.BORNDORFER, M.GROTSCHEL, F.KLOSTERMEINER, C.KUTTNER : «Telebus Berlin : Vehicle routing scheduling in a dial a ride system »; Konrad Zuse Zentrum Technik Berlin, (1997).

[2]. P.COLL, J.MARENCO, I.DIAZ, I. and P. ZABALA: Facets of the graph coloring polytope, Ann. Operat. Res. (116), p 79-90, (2002).

[3]. J.F.CORDEAU, G. LAPORTE: Dial and Ride : models/algorithms ; An. OR 153-1, p 29-46, (2007).

[4]. JF.CORDEAU: A branch and cut algorithm for the Dial/Ride; Oper. Res. 54-3, p 573-586, (2006).

[5]. J.F.CORDEAU, M.GENDREAU, G.LAPORTE, J.Y.POTVIN, F.SEMET : «A guide to vehicle routing heuristics »; Jour. Op. Res. Soc., 53-5, p 512-522, 2002.

[6]. D.CORNAZ, V.JOST: A one to one correspondance between coloring and stable sets, Operat. Res. Letters (36), p 673-676, (2008).

[7]. De PAEPE, K.K.LENSTRA, S.JGALL, R.SITTERS, L.STOUGIE: Computer aided complexity classification of Dial Ride Problems; INFORMS Journal of Computing 22, p 1130-1152, (2004).

[8]. P.FOUILHOUX: Clique branching formulation for the vertex coloring problem, ISCO Conf. Proc. P 120-124, (2012).

[9]. P.HANSEN, M.LABBE, D.SCHINDL: Set covering and packing formulations of graph coloring: algorithms and first polyhedral results, Discrete Optimization (6), p 135-147, (2009).

[10]. L.HIGGINS, J.B.LAUGHLIN, K.TURNBULL: Automatic vehicle location and advanced paratransit scheduling at Houston METROLift; Proc Transport. 2000 Research Board Conf. (2000).

[11]. Y.LUO, P.SCHONFELD: Reinsertion heuristic for DARP; Trans. Res. B 41, p 736-755, (2007).

[12]. E.MALAGUTI, M.MONACCI, P.TOTH: An exact approach for the vertex coloring problem, Disc. Optimization, (2010).

[13]. A.MEHROTRA, M.A.TRICK: A column generation approach for grpah coloring, INFORMS Journal of Computing (8), p 344-354, (1996).

[14]. SCIIP: URL http://scip.zib.de.

[15]. I.MENDEZ-DIAZ, P.ZABALA: A cutting plane algorithm for graph coloring, Disc. Applied Math. 154, p 826-847, (2006).

[16]. K. PALMER, M.DESSOUKY, T.ABELMAGUID: Impact of management practices and advanced technologies on demand responsive transit systems; Transportation Research A 38, p 495-509, (2004).

[17]. C.H.PAPADIMITRIOU, M.YANNANAKIS : « Scheduling interval ordered tasks »; SIAM Journ. Computing 8, pp 405-409, (1979).

[18]. A.QUILLIOT, S.DELEPLANQUE: Constraint propagation for the Dial and Ride problem wit split loads, Studies in Computational Intelligence, Vol 470, p 31-50, Springer, (2013). 